\title{
The Impact of TQM on Employee Performance Abu Sheikha Exchange Company: Case Study
}

\author{
Professor Dr. Aktham Al-Sarayreh, Al-Shatnawi Amal, Al-Madhoun Rasha, Al-Faqeeh \\ Nawal, Mousa Ayoub, Al- Tarawneh Salem, Al-Hlool Mohammad, Smadi Qais, Al-Samoor \\ Mai, Al-Akra Yelena, Sliehat Osama, Hussain Mais, Qowar Musa \\ Amman College University - Al Balqa’ Applied University
}

Received: April 9, 2019 Accepted: April 28, 2019 Online published: May 5, 2019

doi:10.5296/ijhrs.v9i2.14636 URL: https://doi.org/10.5296/ijhrs.v9i2.14636

\begin{abstract}
The aim of this study is to identify (TQM) implementation, and its effect on employee job performance level at Abu Sheikha Exchange Company. Typical descriptive studies are concerned with the assessment of demographic information, support senior management of the work procedures, expectations and needs and wishes of customers, expectations and needs and wishes of employees, continuous improvement, work procedures and engaging staff in decision-making.

The research design is chosen for the current study is the survey research: The target population of this study which consists of all employees in Abu Sheikha Exchange Company. Sample of (133) employees, a questionnaire is developed to measurement of variables study; TQM implementation variable (reliability coefficient 0.937 ), and employee job performance variable (reliability coefficient 0.71 ).

The conclusion of the study shows that the senior management support was in Average level, but the senior management adopts a strategic plan to achieve quality in all areas of the company in high level, Customers' needs and expectations was in High Level, and the result shows that one of the priorities of the company's employees is to satisfy the needs and desires of the customers.
\end{abstract}

Keywords: total quality management, job performance, ABU Sheikha Exchange Company

\section{Introduction}

In the present context of globalization of economy, every company faces a lot of challenges. Before the era of liberalization; it was not quite common to emphasize the quality of products, systems and procedures and customer focus, etc. But after the liberalization process companies survival in an increasingly competitive market closely depends on its ability to 
produce the highest quality product at the lowest possible cost. This calls total quality management of the organization (Kumar, V. 2010). Therefore, (Juran 1995) points out that where as the 20th century become famous for world productivity, the 21 st century would become well recognized as the "century for quality".

According to (Flynn et al. 1994) TQM is "A management philosophy for continuously improving overall business performance based on leadership, supplier quality management, vision and plan statement, evolution, process control and improvement, product design, quality system improvement, employee participation, recognition and reward, education and training, and customer focus".

\section{Problem of the Study}

The researchers noted that there is insufficient awareness of the impact of Total Quality Management on employee performance in the Exchange Companies operating In Jordan. The researchers also recognized that it is important to study this impact by seeking to improve Total Quality Management and the performance of the employees in the exchange sector. This has been an incentive to observe the impact of Total Quality Management on employee performance at Abu Sheikha Exchange in Jordan.

\section{Objectives of the Study}

The study aims at identifying the impact of Total Quality Management on employee performance in Abu Sheikha Exchange Company with a view to identify the level of the application of Total Quality Management and employee performance in Abu Sheikha Exchange Company.

\section{Significance of the study}

The significance of the study stems from two aspects:

\section{First: Theoretical significance}

The importance of the current study is highlighted by the intellectual enrichment that may contribute in terms of tracking the theoretical literature and previous studies related to the main variables adopted in this study, whether independent or dependent ones in the form that constitutes an integrated conceptual framework about their correlation, characteristics , models and methodology of study; Because these variables are contemporary and have an influential nature in the life of the Exchange Companies operating in Jordan, what gives them efficient performance and creativity, in addition to the theoretical importance that was examined in the field of variables of study through implementing Total Quality Management. Moreover, the study becomes more important for reason of it is studies a sample of the Exchange Companies operating in Jordan, the study is important because it addresses Total Quality Management that enables these companies to survive and compete in a market that is highly complex and competitive weather internally or externally. This study is designed to examine the impact of TQM on employee performance at Abu Sheikha Exchange Company.

Second: Practical significance 


\section{Macrothink}

International Journal of Human Resource Studies

ISSN 2162-3058

2019, Vol. 9, No. 2

The practical significance stems from the results of the current study interest in the Exchange Companies operating in Jordan, in a way that helps them to achieve excellence. Moreover, the current study derives its weight from the following points:

1. The results of this study are expected to benefit the managers of the exchange companies operating in Jordan through their knowledge of the application of TQM in the Exchange Companies for which they work.

2. It is hoped that this study will provide new knowledge regarding the application of TQM, which may benefit those managers in planning the future of TQM in Exchange Companies.

3. This study compels in that it will head a topic related to application

Of Total Quality Management in the Exchange Companies operating in Jordan.

4. It is hoped that this study will lead many researchers to perform more new researches in this field, through its theoretical literature, previous studies and research tools that have been verified and validated in this research, which can be used in future studies.

5- Jordan is a center of trade regionally and globally. As a result, this will increase the competitiveness among exchange companies in order to facilitate commercial procedures. Due to the significance of this sector in general, and in Jordan in particular, it is recommended to consider this research useful in this vital sector.

\section{Hypotheses of the study}

H0: There is no statistically significant impact of TQM (Support senior management of the work procedures. Expectations, needs, and wishes of customers. Expectations, needs and wishes of employees, Continuous improvement, work procedures, engaging staff in decision-making) on employee performance at Abu Sheikha Exchange Company.

\section{Study Model:}

\begin{tabular}{|l|}
\hline \multicolumn{1}{|c|}{ Total Quality Management } \\
\hline Support senior management of the work procedures \\
\hline Expectations, needs, and wishes of customers \\
\hline Expectations, needs, and wishes of employees \\
\hline Continuous improvement \\
\hline Work procedures \\
\hline Engaging staff in decision-making \\
\hline
\end{tabular}




\section{Macrothink \\ International Journal of Human Resource Studies \\ ISSN 2162-3058 \\ 2019, Vol. 9, No. 2}

\section{Definition of Independent Variables TQM}

Conforming to (Oakland 1989) TQM is an "approach to improving the effectiveness and

Flexibility of business as a whole. It is essentially a way of organizing and involving the whole organization; every department, every activity, every single person at every level".

\section{Expectations, Needs, and Wishes of Customers}

Basically, a need is a conscious feeling of deprivation in a person. In other words, it is something which a customer requires to reach satisfaction. A want is a need after it has been influenced by culture, society and an individual's personality. There are two kinds of wants, a 'tangible' want and a 'psychological' want, (Camilleri, 2018).

\section{Continuous Improvement}

Continuous quality improvement (CQI) is the systematic process of identifying, describing, and analyzing strengths and problems, and then testing, implementing, learning from, and revising solutions. (David el2014)

\section{Work Procedures}

Written instructions intended to document how to perform a routine activity. Many companies rely on standard operating procedures to help ensure consistency and quality in their products. Standard operating procedures are also useful tools to communicate important corporate policies, government regulations, and best practices, (Wilson 1994)

\section{Engaging Staff in Decision Making}

Employee participation can be defined as the degree to which employees in a firm engage in various quality management activities. By personally participating in quality management activities, employees acquire new knowledge, see the benefits of the quality disciplines, and obtain a sense of accomplishment by solving quality problems however; Participation is decisive in inspiring action on quality management, (Juran and Gryna, 1993)

\section{Expectations, Needs, Wishes of Employees}

Things that an employee expects form an organization, the team and role. are the two basis for employee satisfaction or dissatisfaction (Porter el, 1973)

\section{Support Senior Management of the Work Procedures}

TQM implementation must be started by the senior management because they are the primary internal change agents for quality improvement. Furthermore, they must realize that TQM is a long-term business strategy. The senior management has two major roles:

1. They shape organizational values and establish a managerial infrastructure to actually bring about change.

2. They have to prepare themselves with knowledge about the criteria of TQM, and put in their mind the TQM agenda (Baba el, 2009) 


\section{Literature Review}

(Esaki, K2016) proposing the Common Management Process Model of Total Quality Management based on the consideration of situation analysis. The result of this study discloses that it is thought that the "Common Management Process Model"" suggested it is applicable to each process management domain of new total quality Management". Furthermore, it is thought that the "PDCA" cycle of process has the "Negative Risk" for the essential solution to "Problem" and "Issue" until now. This research recommends that the future study shall try the development of an example of application to make use of "common management process model suggested" as future in the unification management of the organization or system.

A study conducted by (Thawabtah ,2016) aims to identify the effects of applying Total Quality Management strategy on the Human Resources Management practices on a sample of commercial banks operating in the West Bank. The results of this study have detect the presence of a positive statistically significant relationship between the elements of total quality management strategy, and the elements of human resource management practices in commercial banks operating. About the recommendations, the most important ones are the need to continuous application of the total quality management principles, since these principles have a proven impact on the practices of human resources, which means the need to embody these principles to be integrated within the organizational culture of these banks, and to become part of the organizational culture.

(Abd-Elwahed\& El Baz, 2018) broached an interesting argument about way to measure the level of knowledge, understanding, and implementation of quality management tools in a sample of the industrial sector in Saudi Arabia. In addition, this study aims to monitor the different policies to implement the quality strategies and the extent of their integration into the industrial management systems in general. The influence of the executive method of management and its compatibility with the proper implementation of quality tools. The results of the study shows that different visions of strategies of Quality Management and policies are still adopted by industrial companies participating in the survey. In addition, there is difference in the levels of understanding and implementing of Quality Management tools and techniques.

The relationship between TQM on the employee performance in Malaysian manufacturing industry is studied by (Zakuan and Zahari, 2016).The findings shows that Total Quality Management practices have a significant impact on employee performance. The researchers highlight the significance of the people component in the firms of reputation and performance.

They found out that human factor is one of the determining variables besides environmental factors and organizational factors on the organizational culture, which influence employee behaviors and organization performance .Therefore, TQM practices, will helps to enhance the employee performance.

A study examined by (Dedy A.N et al, 2017) indicates that the most critical success factor for Total Quality Management practices was the customer focus. The objective of this study is to analyze the relationship between TQM practices, process innovation and employee 
performance.

Accordingly, employee satisfaction is identified as the critical success factor for the employee performance based on the ranking. The third objective is to explore the effect of Process Innovation mediator toward Total Quality Management to employee performance in automotive industry.

The results of this study reveal that there is a positive correlation among dimensions of Total Quality Management practices. Besides, there is also a strong correlation appeared between dimensions of Total Quality Management practices and EP (employees performance). Furthermore, the direct positive relationship is confirmed to exist between the Total Quality Management with PI (Process Innovation), Total Quality Management with EP and PI with EP.

A study carried out by (Ozdal and Oyebamiji, 2018). The conclusion of this study is to evaluate the implementation of Total Quality Management, and its impact on employees' performance in a tertiary-level teaching hospital in Oyo State, Nigeria. The findings of the study clarify that the implementation of the principles of TQM practices range from leadership to employees' satisfaction. Financial and political pressures were found to be important external factors affecting employees' performance in the particular hospital. These findings give a better understanding on the improvement and promotion of total quality management practices its impact on employees' performance in the healthcare organizations as well as improve effectiveness, productivity, profitability and flexibility of the hospital facilities and services provided to patients/clients.

\section{Methodology}

\section{Introduction}

This chapter describes the methodology that the current study uses, population, sample, tools and data collections, the validity of questionnaire and reliability analysis that is applied is clearly stated. Finally, Discussion of statistical treatment that used in the analysis of the collected data addressed.

\section{Study Methodology}

Typical descriptive studies are concerned with the assessment of attitudes, opinions, demographic information, conditions, and procedures. The research design that is chosen for the current study is the survey research. The survey is collected data from members of the population in order to determine the current status of that population, with respect to one or more variables. The survey research of knowledge at its best can provide every valuable data. It involves a careful design and execution of each of the components of the research process. The researchers designed a survey instrument that is administrated to the research sample. The purpose of the survey instrument is to collect data about the attitudes and opinions toward the impact Total Quality Management on the Job Performance in Abu Shaikah Exchange Company in Jordan. 


\section{Mll Macrothink \\ International Journal of Human Resource Studies \\ ISSN 2162-3058 2019, Vol. 9, No. 2}

\section{Primary and Secondary Sources: Primary Sources:}

The research is based on primary sources including books, and documentaries, to build the questionnaire and the responses.

\section{Secondary Sources:}

The research is based on Journal articles, Abstracts of articles and books.

\section{Data Collection:}

Quantitative approaches used a systematic standardized approach and employ methods such as surveys, and in this study relied on data collection of the questionnaire, and the study sample responses.

\section{Study tool:}

Questionnaire: this questionnaire consists of three sections, Divided as follow are:

- Section One: Demographic Variables, it contains (Age, Academic qualification, Years of experience and career level).

- Section Two: Total quality Management, it contains (Support senior management of the work procedures, expectations, needs, and wishes of customers, expectations and needs as well as the wishes of employees, continuous improvement, work procedures, and engaging staff in decision making).

- $\quad$ Section Three: Job Performance.

\section{Validity}

To test the questionnaire for clarity and to provide a coherent research questionnaire, a macro review that covers all the research constructs is performed accurately by academic reviewers from Jordan University and other universities experts in business administration. The questionnaire is submitted to (7) reviewers, to verify the sincerity of its paragraphs, and to take their opinions, in addition to the re-wording of some paragraphs.

\section{Reliability of TQM questionnaire}

The reliability of this TQM questionnaire is assessed by using Cronbach's alpha for the total scale which is 0.937 and each dimension as shown in Table 1

Table 1. Reliability Coefficients for TQM questionnaire

\begin{tabular}{|l|l|}
\hline Dimension & Cronbach's alpha \\
\hline Job Performance: & 0.715 \\
\hline Overall reliability & 0.937 \\
\hline
\end{tabular}


Table 2. Socio-demographic characteristics

\begin{tabular}{|l|l|l|l|}
\hline \multicolumn{2}{|l|}{ Variable } & $\mathrm{N}$ & $(\%)$ \\
\hline \multirow{4}{*}{ Age } & Less than 25 & 31 & $23.3 \%$ \\
\cline { 2 - 4 } & $26-35$ & 97 & $72.9 \%$ \\
\cline { 2 - 4 } & Greater than 35 & 5 & $3.8 \%$ \\
\hline \multirow{3}{*}{$\begin{array}{c}\text { Academic } \\
\text { qualification }\end{array}$} & Diploma or less & 22 & $16.5 \%$ \\
\cline { 2 - 4 } & Student & 3 & $2.3 \%$ \\
\cline { 2 - 4 } & Graduate & 108 & $81.2 \%$ \\
\hline \multirow{4}{*}{ Career level } & Under 5 years & 93 & $69.9 \%$ \\
\cline { 2 - 4 } & 6 years to 10 years & 31 & $23.3 \%$ \\
\cline { 2 - 4 } & More than 10 years & 9 & $6.8 \%$ \\
\hline & Senior Management & 5 & $3.8 \%$ \\
\cline { 2 - 4 } & Middle management & 61 & $45.9 \%$ \\
\cline { 2 - 4 } & Minimum management & 67 & $50.4 \%$ \\
\hline
\end{tabular}

Socio-demographic characteristic among Abu Shikha Exchange Company employees

The second table revels to the participants general information. Most of the participants' age is between $26-35$ years $(72.9 \%)$. $81.2 \%$ of participants have graduate studies, while only $2.3 \%$ are students. The majority of the participants $(69.9 \%)$ have working experience less than 5 years and half of them $(50.4 \%)$ have minimum management level while only 5 out of 133 participants are on top management level.

\section{Data analysis techniques:}

To answer the study questions and hypothesis which are formulated to examine the impact of Total Quality Management in the Job Performance, a Statistical Package for Social Sciences (SPSS) to analyze the collected data and test the research hypotheses. The following statistical techniques and tests are used in data analysis:

1. Cronbach's Alpha reliability (a) to measure strength of the correlation and coherence between questionnaire items and highlights the stability of consistency with which the instrument measures the concept and helps to assess the 'goodness' of a measure.

$2 \quad$ Frequencies and percentages are used demographical variables.

3. Descriptive Statistical Techniques: these included means and standard deviations. These techniques are used to illustrate respondents to study fields.

4. Multiple Regression is used to examine the hypothesis.

5- The research type scale includes five Likert scale as follows:

\section{Results}

\section{Introduction}

According to the purpose of the research and the research framework presented in the previous 
chapter, this chapter describes the results of the statistical analysis for the data collected according to the research questions and research hypotheses. The data analysis includes a descriptive of the Means and Standard Deviations for the questions of the study, multiple regression test is used.

\section{TQM implementations}

\section{Senior management support}

The standard deviations of the items related to the dimension "senior management support to the employees" at Abu Shikha Exchange Company. All of the participants answer them completely (133). The item (The senior management adopts a strategic plan to achieve quality in all areas of the company) has the highest mean rank in comparison to the others (mean=3.93), while item (2); senior management aims to reduce the amount of work required according to the workload participants has the lowest mean rank (mean=2.98).

\section{Customers' needs and expectations}

The means and standard deviation of the items regarding the customers' wishes and expectations dimension at Abu Shikha Exchange Company. All of the participants answer them completely (133). With a mean of 4.68, the staff agree that satisfying the needs and desires of the customers is one of the company priorities.

\section{Employees Needs and Expectations}

The means and standard deviations of the items on employees' expectations and wishes dimension at Abu Shikha Exchange Company. Top wishes among the employees are related to item (13); in which the staff expect the company holds training courses to raise the ability of employees to meet the needs of customers. However, less mean is resulted for item (11) as the staff less likely expect the company rewards employees who disclose work errors $($ mean=2.74).

\section{Continuous Improvement}

The means and the standard deviations of the items related to how much there is a continuous improvement in Abu Shikha Exchange Company. Out of the total items, it is found that "senior management has the enthusiasm and desire to consistently deliver the best through continuous improvement" has the highest rank mean (4.05).

\section{Work procedures}

The item related to the responsibility of quality improvement among everyone in the company, has the highest mean $($ mean=4.40).

\section{Engaging staff in decision-making}

It is clear the staff agreed on the efforts made by the company that works to make employees work as a team to take advantage of time (mean=3.57). However, lower mean resulted for the item $(25,26)$ in which the staff perceived the department doesn't encourage participation of policy and action planners, and the company's management isn't concerned with the feedback 
of employees that aim to improve quality (mean= 2.90, 2.92respectively).

\section{Job performance}

The means and standard deviations of the items related to the Job performance level in Abu Shikha Exchange Company. For items $(27,33)$ the mean of job performance level is the highest (4.17, 4.20respectively) compared to the other items. While it comes to the lowest mean when the company provides all requirements of work (mean=3.34).

\section{Relationship between TQM implementations and Job Performance level}

A multiple regression is conducted to test the effect of TQM dimensions on the job performance (Dependent Variable).

From the table 3 below, it is clear that TQM dimensions (Engaging staff in decision-making, expectations, needs, and wishes of customers, support senior management of the work procedures, continuous improvement, work procedures, expectations and needs and wishes of employees) explain about $41.6 \%$ of the variance on the job performance variable, thus the TQM implementations significantly affect in the job performance $(\underline{P}=0.000)$. However, it is clear from table 3 that not all TQM dimensions have a significance impact on the job performance. at significance level 0.05, expectations and needs and wishes of customers, engaging staff in decision-making, and support of senior management are the dimensions which significantly affect the dependent variable "Job performance" ( P values: .011, .029, .007respectively).

Table 3. Relationship between TQM implementations and Job Performance

\begin{tabular}{|c|c|c|c|c|c|c|c|c|}
\hline TQM dimensions & B & S.E & Beta & $\mathrm{t}$ & $P$-value & $\mathrm{R}^{2}$ & $f$ & $P$-Value \\
\hline $\begin{array}{l}\text { Support senior } \\
\text { management of the } \\
\text { work procedures }\end{array}$ & .200 & .072 & .254 & 2.764 & .007 & \multirow{6}{*}{$\begin{array}{c}.41 \\
6\end{array}$} & \multirow{6}{*}{14.969} & \multirow{6}{*}{0.000} \\
\hline $\begin{array}{l}\text { expectations and } \\
\text { needs } \\
\text { and wishes of } \\
\text { customers }\end{array}$ & .199 & .077 & .202 & 2.587 & 011 & & & \\
\hline $\begin{array}{c}\text { Expectations and } \\
\text { needs and wishes of } \\
\text { employees }\end{array}$ & .027 & .083 & .040 & .326 & .745 & & & \\
\hline $\begin{array}{l}\text { Continuous } \\
\text { improvement }\end{array}$ & .138 & .084 & .171 & 1.641 & .103 & & & \\
\hline Work procedures & -.064 & .078 & -.090 & -.815 & .416 & & & \\
\hline $\begin{array}{l}\text { Engaging staff in } \\
\text { decision-making }\end{array}$ & .146 & .066 & .229 & 2.205 & .029 & & & \\
\hline
\end{tabular}

\section{Discussion and Conclusion:}

The study shows that senior management support was in average level, but the senior management adopts a strategic plan to achieve quality in all areas of the company in high level. 
- $\quad$ The study shows that Customers' needs and expectations are in High Level and the result show that one of the priorities of the company's employees is to satisfy the needs and desires of the customers.

The study shows that Employees needs and expectations was in Average level, but the Management pays close attention to its staff as valuable assets in the high level.

The Continuous improvement is on the high level and the senior management has the enthusiasm and desire to consistently deliver the best through continuous improvement is on the high level.

- Work procedures are in the high level, but The Company works to provide the organizational climate and the work environment that encourages continuous change is in average level.

The Engaging staff in decision-making is in average level and all statements were in average level as Employees are involved in strategic decision-making related to quality.

The results show that job performance is in the high level and the employees abide by the regulations and rules of the company were in the high level.

The results shows that Support senior management of the work procedures, expectations and needs and wishes of employees and engaging staff in decision-making have an impact on job performance in Abu Shaikah Exchange Company and don't have any impact of expectations and needs and wishes of employees, Continuous improvement and Work procedures on job performance in Abu Shaikah Exchange Company in Jordan.

Acceptance of alternative hypothesis which states that there is significant effect for TQM implementation (Support senior management of the work procedures. Expectations, needs, and wishes of customers, engaging staff in decision-making) on employee performance at Abu Sheikha Exchange Company.

- Acceptance of null hypothesis which states that there is no significant effect for TQM implementation (Expectations, needs and wishes of employees, Continuous improvement, work procedures) on employee performance at Abu Sheikha Exchange Company.

\section{Recommendations}

In light of the findings of the study, we present a number of recommendations which aim

Achieving the TQM implementation in exchange Companies operating in Jordan, including the following:

1. The importance of activating the application of TQM in the exchange companies operating in Jordan.

2. A key principle of TQM is the involvement of employees in decision making process, and if such principle is duly applied, then employees' performance would be more efficient and effective what would be reflected on the total performance of the exchange company.

3. It is recommended to carry out further in depth research in the field of the efficient TQM Application at the exchange companies operating in Jordan. 


\section{Acknowledgement}

The research is supported by the Head Manager of Abu Sheikha Exchange Company Mr. Yasser Abu Sheikha.

\section{References}

Abd-Elwahed, \& El Baz. (2018). Impact of Implementation of Total Quality Management: An Assessment of the Saudi Industry. South African Journal Industrial Engineering, 29(1), 97-107.

Aimie, N. D. et al. (2016). An analysis of total quality management on employee performance with mediating role of process innovation. IOP Conf. Ser.: Mater. Sci. Eng. 131, 01, 2017.

Baba, M. el (2009). Role of Senior Management in TQM Implementation in Malaysian Small and Medium Enterprises. Journal The Institution of Engineers, Malaysia (Vol. 72, No.3)

Camilleri, M. A. (2018). Travel Marketing, Tourism Economics and the Airline Product, p 7, Springer. International Publishing AG.

David, L., \& Goetsch, D. (2014). Quality management for organizational excellence: introduction to total quality ,Pearson, new York, p 2.

Esaki, K. (2016) Common Management Process Model of New TQM Based on the Situation Analysis. Intelligent Information Management, 8,181-193.

Flynn, R. G., Schroeder, \& Sakakibara, S. (1994). Framework for quality management research and an associated instrument, Journal of Operations Management, 11(4), (1994), 339-366.

Joseph, M. J., \& Frank, M. G. (1993). Quality Planning and Analysis: From Product Development Through Use. McGraw-Hill.

Juran, J. M. (1995). Summary, trends, and prognosis. A history of managing for quality: The evolution, trends, and future directions of managing for quality. Milwaukee, WI: ASQ Quality Press.

Kumar, V. (2010). JIT Based Quality Management: Concepts and Implications in Indian Context. International Journal of Engineering Science and Technology. (Vol. 2, No. 1, pp. 40-50).

Macide, A. O., \& Bamise, F. O. (2018). Implementation of Total Quality Management and its Effect on Employees' Performance in a Teaching Hospital in Oyo State, Nigeria. Public H Open Acc 2018.

Oakland, J. S. (1989). Total Quality Management, Heinemann Professional, London.

Porter, L. W., \& Steers, R. M. (1973). Organizational, work, and personal factors in employee turnover and absenteeism. Psychological Bulletin.

Thawabtah, M. (2016). The Effect of Applying Total Quality Management Strategy on the 
Human Resources Management Practices on a Sample of Commercial Banks Operating in the West Bank. Middle East University.

Wilson, T. D. (1994). Tools for the analysis of business information needs. Aslib Proceedings, London, 46(1).

Zakuan, \& Zahari. (2016). The Effects Of Total Quality Management On The Employee Performance In Malaysian Manufacturing Industry. South African Journal of Industrial Engineering May 2015, 26(1), 75-85

\section{Copyright Disclaimer}

Copyright for this article is retained by the author(s), with first publication rights granted to the journal.

This is an open-access article distributed under the terms and conditions of the Creative Commons Attribution license (http://creativecommons.org/licenses/by/4.0/). 